\title{
Diapycnal diffusivities from a tracer release experiment in the deep sea, integrated over 13 years
}

\author{
Craig D. Rye, ${ }^{1}$ Marie-Jose Messias, ${ }^{1}$ James R. Ledwell, ${ }^{2}$ Andrew J. Watson, ${ }^{1}$ \\ Andrew Brousseau, ${ }^{1}$ and Brian A. King ${ }^{3}$ \\ Received 9 November 2011; revised 19 January 2012; accepted 19 January 2012; published 21 February 2012.
}

[1] A section across the Atlantic at $24^{\circ} \mathrm{S}$ recorded in March 2009, sampled a tracer plume released in the deep Brazil Basin 13 years earlier. The 1-D diffusion equation was used to model the vertical spread of the tracer, yielding a mean diapycnal diffusivity estimate of approximately $3 \times 10^{-4} \mathrm{~m}^{2} / \mathrm{s}$ at $4 \mathrm{~km}$ depth. This estimate is similar to that found by surveys of the tracer plume made between 1996 and 2000, within four years of the tracer release and therefore provides strong evidence for the long-term stability of that result. Citation: Rye, C. D., M.-J. Messias, J. R. Ledwell, A. J. Watson, A. Brousseau, and B. A. King (2012), Diapycnal diffusivities from a tracer release experiment in the deep sea, integrated over 13 years, Geophys. Res. Lett., 39, L04603, doi:10.1029/ 2011 GL050294.

\section{Introduction}

[2] Information regarding the variability and magnitude of apparent eddy diapycnal (cross isopycnal) diffusivity in the lower limb of the Atlantic Meridional Overturning Circulation (AMOC) is important in the study of ocean heat and tracer transport. Webb and Suginohara [2001], even while arguing for a minimal role of diapycnal mixing in governing the overturning circulation of North Atlantic Deep Water (NADW), allowed that as much as $5 \mathrm{~Sv}$ of those waters upwell as a result of diapycnal mixing at "hot spots". Furthermore, Hogg et al. [1982] and Morris et al. [2001] showed that a diapycnal diffusivity of 2 to $4 \times 10^{-4} \mathrm{~m}^{2} / \mathrm{s}$ is required to satisfy the buoyancy and mass budgets of water entering the deep Brazil Basin with potential density $\sigma_{4}$ greater than $45.98 \mathrm{~kg} / \mathrm{m}^{3}$. However it is clear from direct measurements that diffusivity is spatially variable [Polzin et al., 1997; Ledwell et al., 2000]; increased understanding of this variability is key in the study of abyssal dynamics and their importance for the AMOC.

[3] From 1996 to 2000, the Brazil Basin Tracer Release Experiment (BBTRE) was a concerted effort to directly measure isopycnal and diapycnal diffusivity in the abyssal waters of the Brazil Basin. BBTRE utilized the release of a patch of sulfur hexafluoride $\left(\mathrm{SF}_{6}\right)$, neutrally buoyant floats and profiler measurements of the rate of dissipation of turbulent kinetic energy. In February $1996,110 \mathrm{~kg}$ of SF${ }_{6}$ were released on the $45.9408 \mathrm{~kg} / \mathrm{m}^{3}$ potential density surface $\left(\sigma_{4}\right)$, at approximately $4000 \mathrm{~m}$ depth near $21.7^{\circ} \mathrm{S}, 18.4^{\circ} \mathrm{W}$

\footnotetext{
${ }^{1}$ School of Environmental Sciences, University of East Anglia, Norwich, $\mathrm{UK}$. USA.

${ }^{2}$ Woods Hole Oceanographic Institution, Woods Hole, Massachusetts,

${ }^{3}$ National Oceanography Center, Southampton, UK.
}

Copyright 2012 by the American Geophysical Union. 0094-8276/12/2011GL050294
(Figure 1). Surveys of the patch were conducted in 1997, 1998 and 2000. The majority of tracer was observed to travel south-west while a considerable amount (30\% in 1998) had moved east of the release site. As much as 2 or $3 \%$ of the tracer appeared to have passed through the Mid Atlantic Ridge (MAR) into the Angola Basin by the 2000 survey (unpublished). Monitoring the change in tracer distribution between release and later surveys provided a diapycnal diffusivity estimate of $k=(3.0 \pm 1) \times 10^{-4} \mathrm{~m}^{2} / \mathrm{s}$ at $\sim 4 \mathrm{~km}$ depth [Ledwell et al., 2000]. Increase in the lateral area of the patch indicated an unusually constant isopycnal diffusivity of $100 \mathrm{~m}^{2} / \mathrm{s}$, independent of the scale of the patch (unpublished).

[4] Prior to the release and during the survey cruise in 1997 a free falling turbulence instrument, the High Resolution Profiler [Schmit et al., 1988], was used to estimate diffusivities for density, $k_{\rho}$, ranging from $0.1 \times 10^{-4} \mathrm{~m}^{2} / \mathrm{s}$ in the central basin to values greater than $5 \times 10^{-4} \mathrm{~m}^{2} / \mathrm{s}$ within $150 \mathrm{~m}$ of the sea floor over the MAR, on the eastern side of basin. A value of $k_{\rho}=(2.3 \pm 1) \times 10^{-4} \mathrm{~m}^{2} / \mathrm{s}$ for the tracer release region was also estimated [Polzin et al., 1997; Ledwell et al., 2000].

[5] In 2009, thirteen years after the release, an opportunistic section through the BBTRE tracer was performed allowing for a long-term estimate of diapycnal diffusivity in the basin.

\section{Method}

[6] The distributions of the sulfur hexafluoride and transient chlorofluorocarbons (CFCs) along a hydrographic section at $24^{\circ} \mathrm{S}$ were documented as part of the U.K observational project, "Oceans 2025" aboard RRS James Cook from March to April 2009 (Figures 1 and 2). Water samples were collected using Niskin bottles in a CTD Rosette. $\mathrm{CFC} / \mathrm{SF}_{6}$ samples were the first drawn and sample bottles were overflowed with twice their volume of water before being stoppered, then stored in cold water below $5^{\circ} \mathrm{C}$. CFC-SF 6 analysis was conducted with a system developed at the University of East Anglia from a design proposed by W. Smethie (LDEO, personal communication, 2004). The instrument employs a double purge and trap extraction technique coupled to two gas chromatographs with electron capture detectors, similar to that of Smethie et al. [2000] for CFC analysis and Law et al. [1994] for $\mathrm{SF}_{6}$.

\section{Observations}

[7] Two distinct tracer-tainted areas were observed (Figure 2). The primary tracer plume spans from 26.5 to $13^{\circ} \mathrm{W}$ and intersects the MAR on its western side from $22.5^{\circ} \mathrm{W}$ eastwards, with a mean vertical maximum in tracer concentration on the potential density surface $45.95 \mathrm{~kg} / \mathrm{m}^{3}$ 


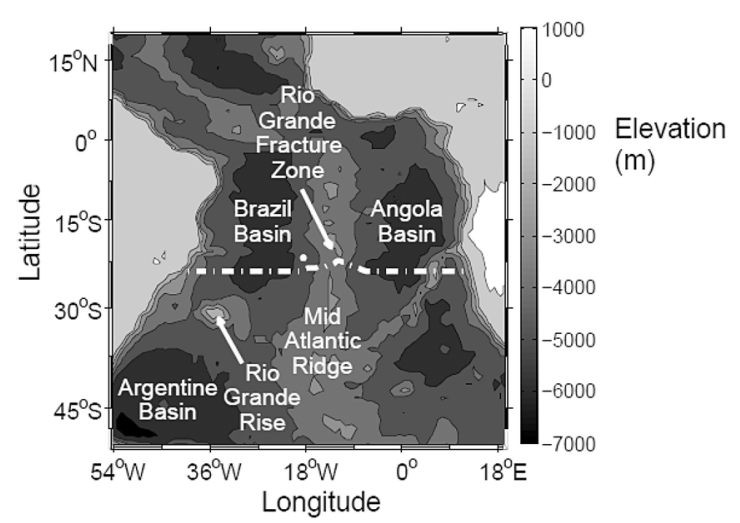

Figure 1. South Atlantic Map. Dashed line: 2009 cruise track. Dot: 1996 tracer release site (base map from Amante and Eakins [2009]).

( $\sigma_{4}$, approximately $4.2 \mathrm{~km}$ depth). A secondary smaller plume of lower concentration can be identified in the west between 32 and $28^{\circ} \mathrm{W}$. A small amount of tracer was found passing through the Rio Grande fracture Zone to the east and into the Angola basin on the eastern flank of the MAR (Figure 2).

\section{Analysis}

[8] Due to the increasing concentration of atmospheric $\mathrm{SF}_{6}$, a substantial background originating from the atmosphere was found at depth. To correct for this the ratios of $\mathrm{SF}_{6}$ to $\mathrm{CFCs}$ were examined in 25 profiles between $4^{\circ} \mathrm{W}$ and $12^{\circ} \mathrm{E}$, a region free of BBTRE tracer. CFC-12 was found to be of most use, with a consistent ratio of background $\mathrm{SF}_{6}$ to $\mathrm{CFC}-12$ of $(5 \pm 0.02) \times 10^{-4}$ between $2000 \mathrm{~m}$ and the sea floor (Figure 3). This background was then subtracted from all $\mathrm{SF}_{6}$ concentrations, leaving the BBTRE plume alone for analysis (Figure 2).

[9] Assuming the diapycnal diffusivity to be constant with depth we applied an unbounded 1D diffusion model for a point release to the vertical distribution of the tracer, ignoring, as an approximation, the effects of lateral dispersion and the presence of the bottom. With these simplifications the vertical tracer distribution should be Gaussian and the

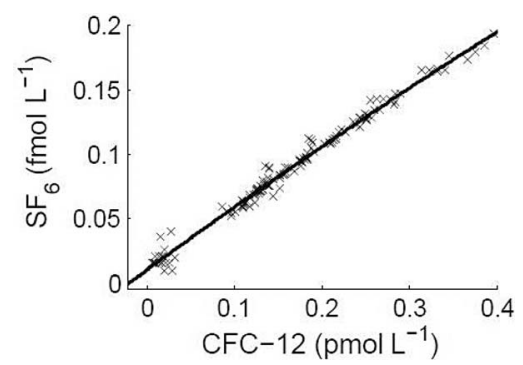

Figure 3. $\mathrm{SF}_{6}$ against $\mathrm{CFC}-12$ concentrations observed during the 2009 survey section in regions free of BBTRE tracer.

diffusivity may be estimated from the growth of the second moment [e.g., Fischer et al., 1979]:

$$
k=\frac{1}{2} \frac{d \sigma^{2}}{d t} \approx \frac{1}{2} \frac{\left(\sigma_{2}^{2}-\sigma_{1}^{2}\right)}{\left(t_{2}-t_{1}\right)}
$$

where $\sigma_{1}^{2}$ and $\sigma_{2}^{2}$ are the mean second moments recorded in 1996 and 2009 respectively and $t_{2}-t_{1}$ is equal to 13 years.

[10] An initial second moment $\sigma_{1}^{2}$ of $81 \mathrm{~m}^{2}$ was reported by Polzin et al. [1997]. In calculating the final second moment only profiles from the 2009 section with tracer gradients below as well as above the vertical maximum in concentration were accepted for analysis. Profiles were interpolated in density space then plotted against an equivalent depth which utilized an average density-depth relation for the tracer region. As in the work by Ledwell et al. [2000] a mean tracer profile was calculated from 15 stations west of $18^{\circ} \mathrm{W}$ with accepted profiles extending to $26.5^{\circ} \mathrm{W}$. A least-squares fit of a Gaussian curve to the mean profile, which is indeed remarkably Gaussian (Figure 4), provided an estimate of the final second moment $\sigma_{2}^{2}$ from which a mean diapycnal diffusivity of $k=(3.3 \pm 1) \times 10^{-4} \mathrm{~m}^{2} / \mathrm{s}$ was estimated from (1). Formal $(1-\sigma)$ uncertainty bounds of the diffusivity estimate were found as the change in the second moment of the Gaussian curve resulting in an increase of chi-squared by one unit, following the situation that would prevail for normal statistics [Bevington and Robinson, 1983]. The uncertainty derived from the mean density-depth relation was explored via comparison to local density-depth relations and found to

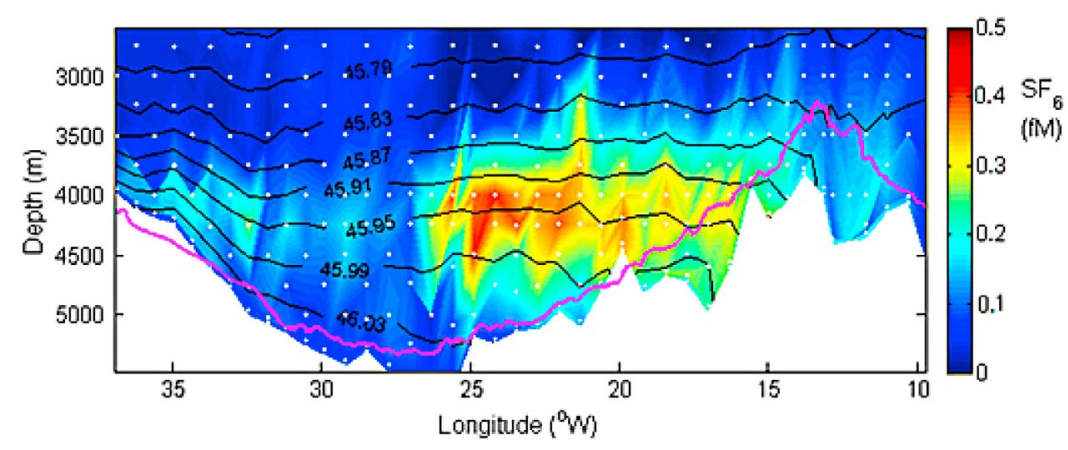

Figure 2. Background subtracted tracer $\left(\mathrm{SF}_{6}\right)$ concentration against depth and longitude across the Brazil Basin section. Potential density isopycnals $\left(\sigma_{4}\right)$ and data points are represented by black lines and white dots respectively, the meridional-mean topography between the release site and the 2009 section $\left(21.5\right.$ to $\left.25^{\circ} \mathrm{S}\right)$ derived from the GEBCO data set [Intergovernmental Oceanographic Commission et al., 2003], is shown by the magenta line. 


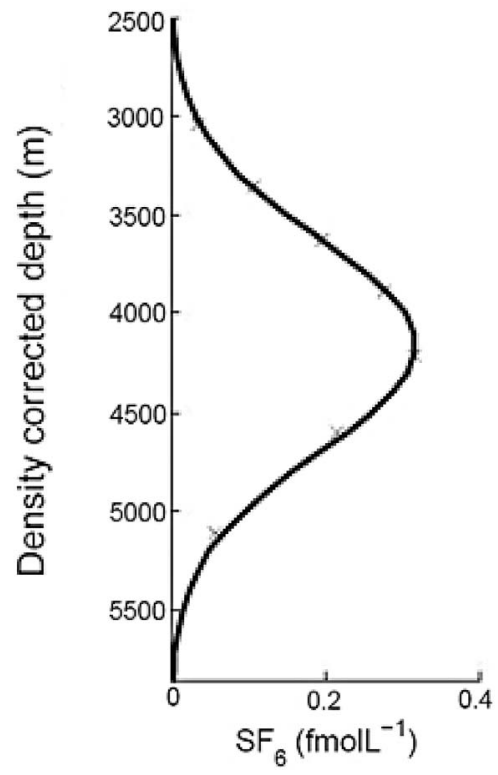

Figure 4. Mean tracer (SF6) profile (dotted line) and Gaussian fit (full line) against depth. Data points are shown as crosses.

be small, resulting in an error in diffusivity estimates of approximately $2 \times 10^{-5} \mathrm{~m}^{2} / \mathrm{s}$. Uncertainties from advective effects and other errors from the assumptions of the simple model used here may well be larger than our formal estimate from the curve fitting exercise

\section{Discussion}

[11] Our estimate of the mean diapycnal diffusivity at $4200 \mathrm{~m}$ depth in the interior Brazil Basin agrees closely with the estimate of $3.0 \pm 1 \times 10^{-4} \mathrm{~m}^{2} / \mathrm{s}$ from the 1997 tracer survey reported by Ledwell et al. [2000]. Coincidentally it also agrees, within uncertainty bounds, with the basin-wide diffusivity estimated by Hogg et al. [1982] and Morris et al. [2001] from the heat budget of the Antarctic Bottom Water entering the Brazil Basin.

[12] The second moment of each vertical profile between $16^{\circ} \mathrm{W}$ and $26.5^{\circ} \mathrm{W}$ was also estimated by fitting Gaussian curves to the individual profiles, as earlier described for the mean profile. These second moments tend to decrease west of $22^{\circ} \mathrm{W}$ (Figure 5) as the distance from the bottom and the MAR increases. The local second moment appears to be approximately constant between $22^{\circ} \mathrm{W}$ and $16^{\circ} \mathrm{W}$, or even to decrease toward the east, perhaps because the presence of the bottom has limited downward transport of tracer in this region, and thus the growth of the second moment. The decrease west of $22^{\circ} \mathrm{W}$ is consistent with the inference of diffusivity of density from turbulent energy dissipation rates by Polzin et al. [1997, Figure 2], with their diffusivity estimate ultimately falling to around $1 \times 10^{-5} \mathrm{~m}^{2} \mathrm{~s}^{-1}$ to the west of $28^{\circ} \mathrm{W}$ where the bottom becomes a smooth abyssal plain. However, firm conclusions from the zonal trend of the local second moment are not possible due to the large uncertainty in the trajectories of the tracer. The 2009 survey consists of a single section through a tracer patch that, after 13 years, must be widespread even if still confined to the Brazil Basin. The question arises of how representative of the whole patch the 2009 section is. As already noted, vertical gradients in the mean flow or in the strength of eddy dispersion can distort the local vertical distribution of the tracer from the simple model we have assumed. The vertical distribution of a (vertically) sheared patch of tracer will be more off-center vertically the further away it is from the horizontal center of the patch. However, the center of the 2009 profiles are near the density surface expected, given the fall rate observed from 1996 to 2000, providing some evidence that interpretation of the latest survey is not in serious error due to shear.

[13] The levels of tracer found in 2009 also suggest the validity of the sample, as follows. The area of the $\sigma_{4}=$ $45.9 \mathrm{~kg} / \mathrm{m}^{3}$ surface within the Brazil Basin is approximately $3000 \mathrm{~km} \times 2000 \mathrm{~km}=6 \times 10^{12} \mathrm{~m}^{2}$. If the tracer were uniformly mixed throughout the basin along this isopycnal, with the observed vertical spread, then the concentration at the center of the vertical profiles would be about $0.1 \mathrm{fM}$. The 2009 survey found concentrations of 0.3 to $0.4 \mathrm{fM}$ east of $27 \mathrm{~W}$ at the center of the vertical distribution and much lower concentrations west of that longitude. If the tracer covered only half or a third of the basin, then we would conclude that the 2009 survey passed through a representative part of the patch.

[14] Further support can be found by invoking the lateral diffusivity of $k_{h}=100 \mathrm{~m}^{2} / \mathrm{s}$ observed during the first four years of dispersion of the tracer (unpublished). If dispersion continued at this rate in an infinite domain (i.e., ignoring the confining effect of the MAR and other boundaries of the basin) then the concentration at the center of the patch would be $1.2 \mathrm{fM}$, the patch distribution would be Gaussian with a lateral standard deviation of $\left(2 k_{h} t\right)^{1 / 2}=286 \mathrm{~km}$ at $t=13$ years. From this idealization one would expect the concentrations found by the 2009 section $(\sim 0.4 \mathrm{fM})$, to be approximately $400 \mathrm{~km}$ away from the center of the patch, with $95 \%$ of the tracer within $600 \mathrm{~km}$ of the release site, suggesting that by 2009 the tracer taints $\sim 1 / 6$ of the Brazil Basin. Following the above arguments it is probable that the 2009 section passed through a representative part of the patch that was not too far from the lateral center of mass.

\section{Summary}

[15] The 2009 South Atlantic section intersected the BBTRE tracer plume along $24^{\circ} \mathrm{S}$ allowing calculation of a 13 year mean diapycnal diffusivity of approximately $3.3 \times$ $10^{-4} \mathrm{~m}^{2} / \mathrm{s}$, consistent with the one-year diffusivity

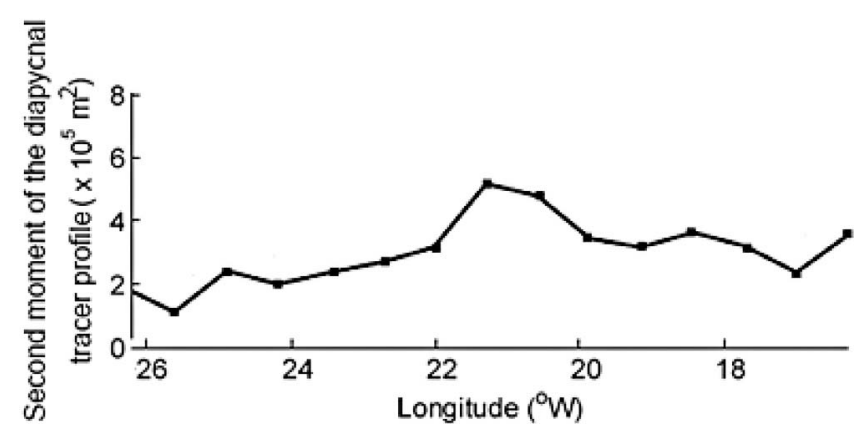

Figure 5. Local values of the vertical second moment of the tracer plume recorded in 2009, against longitude. Data points are shown as square dots. 
calculated from the 1997 BBTRE survey. Although our results suffer from being based on a single section through a large tracer patch, they have the advantage of being the result of an integration over 13 years, and therefore offer strong evidence for the permanence of the level of mixing found in the Brazil Basin Tracer Release Experiment.

[16] Acknowledgments. We would like to thank David Cooper for his work on the tracer measurements during the 2009 research cruise. We would like also to thank the captain and the crew of RRS James Cook. This work was supported by the NERC (National Environmental Research Council) 2025 Ocean program.

[17] The Editor thanks two anonymous reviewers for their assistance in evaluating this paper.

\section{References}

Amante, C., and B. W. Eakins (2009), ETOPO1 1 arc-minute global relief model: Procedures, data sources and analysis, NOAA Tech. Memo. NESDIS NGDC-24, 19 pp., NOAA, Boulder, Colo.

Bevington, P. R., and D. K. Robinson (1983), Data Reduction and Error Analysis for the Physical Sciences, McGraw-Hill, New York.

Fischer, H. B., E. G. List, R. C. Y. Koh, J. Imberger, and N. H. Brooks (1979), Mixing in Inland and Coastal Waters, Academic, New York.

Hogg, N., P. Biscaye, W. Gardner, and W. J. Schmitz (1982), On the transport and modification of Antarctic Bottom Water in the Vema Channel, J. Mar. Res., 40, Suppl., 231-263.

Intergovernmental Oceanographic Commission, International Hydrographic Organization, and British Oceanographic Data Centre (2003), Centenary Edition of the GEBCO Digital Atlas [CD-ROM], Br. Oceanogr. Data Cent., Liverpool, U. K.
Law, C. S., A. J. Watson, and M. I. Liddicoat (1994), Automated vacuum analysis of sulphur hexafluoride in seawater: Derivation of the atmospheric trend (1970-1993) and potential as a transient tracer, Mar. Chem., 48(1), 57-69, doi:10.1016/0304-4203(94)90062-0.

Ledwell, J. R., E. T. Montgomery, K. L. Polzin, L. C. St. Laurent, R. W. Schmitt, and J. M. Toole (2000), Evidence for enhanced mixing over rough topography in the abyssal ocean, Nature, 403(6766), 179-182, doi: $10.1038 / 35003164$.

Morris, M. Y., M. M. Hall, L. C. St. Laurent, and N. G. Hogg (2001), Abyssal mixing in the Brazil Basin, J. Phys. Oceanogr., 31, 3331-3348, doi:10.1175/ 1520-0485(2001)031<3331:AMITBB>2.0.CO;2.

Polzin, K. L., J. M. Toole, J. R. Ledwell, and R. W. Schmitt (1997), Spatial Variability of turbulent mixing in the abyssal ocean, Science, 276(5309), 93-96, doi:10.1126/science.276.5309.93.

Schmit, R. W., J. M. Toole, L. Koehler, C. Mellinger, and K. W. Doherty (1988), The development of a fine- and microstructure profiler, J. Atmos. Oceanic Technol., 5, 484-500, doi:10.1175/1520-0426(1988)005<0484: TDOAFA $>2.0 . \mathrm{CO} ; 2$.

Smethie, W. M., Jr., P. Schlosser, G. Bönisch, and T. S. Hopkins (2000), Renewal and circulation of intermediate waters in the Canadian Basin observed on the SCICEX 96 cruise, J. Geophys. Res., 105(C1), 1105-1121, doi:10.1029/1999JC900233.

Webb, D. J., and N. Suginohara (2001), Vertical mixing in the ocean, Nature, 409(6816), 37, doi:10.1038/35051171.

A. Brousseau, M.-J. Messias, C. D. Rye, and A. J. Watson, School of Environmental Sciences, University of East Anglia, Norwich NR4 7TJ, UK. (craig.d.rye@gmail.com)

B. A. King, National Oceanography Center, Empress Dock, Southampton SO14 3ZH, UK.

J. R. Ledwell, Woods Hole Oceanographic Institution, Mail Stop 12, Woods Hole, MA 02543, USA. 